\title{
MECHANICAL PROPERTIES OF THE 38KhS STEEL AFTER ISOTHERMAL QUENCHING IN THE BAINITIC TEMPERATURE REGION
}

\author{
A. Yu. Kaletin* \\ M. N. Mikheev Institute of Metal Physics, Ural Branch of the Russian Academy of Sciences, \\ 18 S. Kovalevskoy St., Ekaterinburg, Russian Federation \\ *Corresponding author. E-mail: akalet@imp.uran.ru \\ address for correspondence: ul. S. Kovalevskoy, 18, Ekaterinburg, 620990, Russian Federation \\ Tel.: +7 3433783818
}

The mechanical properties of the sparingly alloyed $38 \mathrm{KhS}$ steel with a carbon content of $0.36 \%$ and a silicon content of $1.14 \%$ after different isothermal quenching regimes in the bainitic temperature range with different holding times were investigated. It is demonstrated that, after such heat treatment, the structure of carbide-free bainite represented as a two-phase mixture of carbondepleted bainitic ferrite and carbon-enriched retained austenite with different morphology are formed in the steel. Retained austenite in such carbide-free bainite is substantially enriched with carbon and contains a considerable part of the total carbon content in the steel. It is shown that tempering for $1 . .2$ hours at a temperature of $300{ }^{\circ} \mathrm{C}$ raises the values of impact strength of the $38 \mathrm{KhS}$ steel after isothermal holdings in the bainitic transformation temperature range resulting in the formation of different proportions of lower lath and upper globular bainite, retained austenite and martensite in the structure. It has been found that, under such tempering, stabilization of retained austenite occurs due to noticeably increased carbon content in it.

Keywords: isothermal quenching, carbide-free bainite, retained austenite, bainitic ferrite, carbon, mechanical properties, strength, impact strength.

DOI: $10.17804 / 2410-9908.2017 .6 .064-070$

\section{References}

1. Bhadeshia H.K.D.H. Bainite in Steels, 3d ed., London, The Institute of Materials, 2016, 616 p. ISBN-13: 978-1909662742.

2. Bojarski Z., Bold T. Structure and properties of carbide-free-bainite. Acta Metallurgica, 1974, vol. 22, iss. 10, pp. 1223-1234.

3. Caballero F.G., Bhadeshia H.K.D.H. Very strong bainite. Current Opinion in Solid State and Materials Science, vol. 22, iss. 10, pp. 251-257.

4. Caballero F.G., Santofimia M.J., Garcia-Mateo C., Chao J., Garcia de Andres C. Theoretical design and advanced microstructure in super high strength steels. Materials and Design, 2009, vol. 30, iss. 6, pp. 2077-2083.

5. Caballero F.G., Roelofs H., Hasler St., Capdevila C., Chao J., Cornide J., Garcia-Mateo C. Influence of bainite morphology on impact toughness of continuously cooled cementite free bainitic steels. Materials Science and Technology, 2012, vol. 28, iss. 1, pp. 95-102.

6. Soliman M., Mostafa H., El-Sabbah A.S., Palkovski H. Low temperature bainite in steel with 0, $26 \mathrm{wt} \%$ C. Materials Science and Engineering A, 2010, vol. 527, iss. 29-30, pp. 7706-7713. 7. Shchastlivtsev V.M., Kaletina Yu.V., Fokina E.A. Ostatochniy Austenite v Legirovannykh Stalyakh [Retained Austenite in Alloy Steels]. Ekaterinburg, RIO URO RAN Publ., 2014, 236 p. ISBN 978-5-7691-2384-9. (In Russian).

8. Long X.Y., Kang J., Lv B., Zhang F.C. Carbide-free bainite in medium carbon steel. Materials and Design, 2014, vol. 64, pp. 237-245. 
9. Krishna M.N., Janaki R.G.D., Murty B.S., Reddy G.M., Rao T.G.P. Carbide-free bainitic weld metal: a new concept in welding of armor steels. Metallurgical and Materials Transactions B, 2014, vol. 45, iss. 6, pp. 2327-2337.

10. Kaletin A.Yu., Ryzhkov A.G., Kaletina Yu.V. Enhancement of Impact Toughness of Structural Steels upon Formation of Carbide-Free-Bainite. Physics of Metals and Metallography, 2015, vol. 116. iss. 1, pp. 109-114. DOI: 10.1134/S0031918X15010068

11. Kaletin A.Yu., Kaletina Yu.V. Evolution of Structure and Properties of Silicon Steels in the Austenite-Bainite Phase Transition. Physics of the Solid State, 2015, vol. 57, iss. 1. pp. 56-61. DOI: $10.1134 / \mathrm{S} 106378341501014 \mathrm{X}$

12. Kaletin A.Yu., KaletinaYu.V. Effect of Low-Temperature Tempering on the Properties of Structional Carbide-Free-Bainite Steels. Diagnostics, Resource and Mechanics of Materials and Structures, 2016, iss. 6, pp. 63-68. Available at: http://dream-journal.org/ /DREAM_Issue_6_2016_Kaletin_A.Yu._et_al._063_068.pdf 
Подана в журнал: 15.11 .2017

УДК 669.14.018.29:539.4.015

DOI: $10.17804 / 2410-9908.2017 .6 .064-070$

\title{
МЕХАНИЧЕСКИЕ СВОЙСТВА СТАЛИ ЗЯХС ПОСЛЕ ИЗОТЕРМИЧЕСКОЙ ЗАКАЛКИ В БЕЙНИТНОМ ИНТЕРВАЛЕ ТЕМПЕРАТУР
}

\author{
А. Ю. Калетин \\ Федеральное государственное бюджетное учреждение науки \\ Институт физики металлов имени М.Н. Михеева Уральского отделения Российской академии наук, \\ ул. С. Ковалевской, 18, Екатеринбург, Российская Федераиция \\ *Ответственный автор. Электронная почта: akalet@imp.uran.ru \\ Адрес для переписки: ул. С.Ковалевской, 18, 620990, Екатеринбург, Российская Федерация \\ Тел.: +7 (343) 378-38-18
}

Исследованы механические свойства экономнолегированной стали $38 \mathrm{XC}$ с содержанием углерода $0,36 \%$ и кремния $1,14 \%$ после различных режимов изотермической закалки в бейнитном интервале с различными временами выдержки. Показано, что после таких режимов термической обработки в исследованной стали образуется структура бескарбидного бейнита, представляющая собой двухфазную смесь обедненного по углероду бейнитного феррита и пересыщенного углеродом остаточного аустенита различной морфологии. Остаточный аустенит в бескарбидном бейните существенно обогащен по углероду и содержит значительную часть от общего содержания углерода в стали. Показано, что отпуск при температуре $300{ }^{\circ} \mathrm{C}$ в течение $1 . . .2$ ч повышает значения ударной вязкости стали $38 \mathrm{XC}$ после изотермических выдержек в интервале температур бейнитного превращения, приводящих к образованию в структуре различного соотношения верхнего и нижнего бейнитного феррита, остаточного аустенита и мартенсита. Установлено, что при таком отпуске происходит стабилизация остаточного аустенита за счет заметного повышения в нем содержания углерода.

Ключевые слова: изотермическая закалка, бескарбидный бейнит, остаточный аустенит, бейнитный феррит, углерод, механические свойства, прочность, ударная вязкость.

\section{1. Введение}

В последние годы накоплен обширный материал о промежуточном превращении переохлажденного аустенита [1-4] и свойствах бейнита конструкционных сталей [2-6]. Бейнитная структура имеет сложную природу, и в зависимости от содержания углерода, легирующих элементов и условий охлаждения, может существенно менять свою морфологию. По температуре образования морфологически различают верхний и нижний бейнит. Особенности бейнитного превращения связаны с протеканием при температурах, где отсутствует диффузия атомов железа и легирующих элементов, но происходит интенсивная диффузия углерода. Это обусловливает, во-первых, наличие большого разнообразия морфологических форм образующихся фаз, и, во-вторых, получение разного химического состава этих фаз, отличающихся содержанием углерода. От величины перераспределения углерода в значительной степени зависят особенности структуры и свойства стали после превращения в бейнитной области.

В некоторых случаях после превращения в бейнитном интервале в сталях образуется структура, получившая определение как «бескарбидный бейнит». Как правило, такая структура образуется в сталях, легированных кремнием и алюминием [7-11], однако ее также на- 
блюдали и в низкоуглеродистых легированных сталях без этих элементов после непрерывного охлаждения [12].

Несмотря на большое количество данных, относительно особенностей структуры бескарбидного бейнита, существует ряд нерешенных вопросов, касающихся влияния отпуска на механические свойства низколегированных конструкционных сталей со структурой бескарбидного бейнита.

Целью настоящей работы - исследование влияния отпуска при различных температуpax на поведение остаточного аустенита и механические свойства широко используемой в промышленности стали $38 \mathrm{XC}$ с бескарбидным бейнитом, полученным при изотермических выдержках в бейнитном интервале температур.

\section{2. Материал и методика исследования}

Материалом для исследования служила экономнолегированная промышленная сталь $38 \mathrm{XC}$, химический состав которой представлен в табл. 1.

Таблица 1 - Химический состав исследованной стали, мас. \%

\begin{tabular}{|c|c|c|c|c|c|c|c|}
\hline Сталь & $\mathrm{C}$ & $\mathrm{Cr}$ & $\mathrm{Ni}$ & $\mathrm{Mn}$ & $\mathrm{Si}$ & $\mathrm{S}$ & $\mathrm{P}$ \\
\hline $38 \mathrm{XC}$ & 0,36 & 1,38 & 0,11 & 0,36 & 1,14 & 0,015 & 0,013 \\
\hline
\end{tabular}

Заготовки исследуемой стали нагревали на $870{ }^{\circ} \mathrm{C}$ в расплаве солей, выдерживали 30 мин, после чего подвергали изотермической закалке с различными выдержками в интервале температур бейнитного превращения $\left(360-410^{\circ} \mathrm{C}\right)$.

Структуру сталей изучали электронно-микроскопическим методом на микроскопе JEM-200 CX на фольгах, вырезанных из соответствующих образцов, приготовленных по стандартной методике. Количество остаточного аустенита измеряли магнитометрическим методом. Механические свойства определяли при комнатной температуре статическим растяжением пятикратных образцов с диаметром рабочей части $5 \mathrm{~mm}$. Ударную вязкость определяли на образцах типа I по ГОСТ 9454-78. Для определения параметра решетки остаточного аустенита на аппарате ДРОН-3.0 в $K_{\alpha}$-излучении железа снимали линию (311) $\gamma$. Полученные данные использовали для расчета содержания углерода в остаточном аустените по методике [2].

\section{3. Результаты исследования и обсуждение}

Раздельное влияние низкотемпературного отпуска на свойства стали с глобулярной и реечной формой бейнитного феррита изучали на стали $38 \mathrm{XC}$, в которой, как известно [6], результатом промежуточного превращения и в нижнем, и верхнем температурном интервале является бескарбидный бейнит. По данным работ [6,7], после изотермической закалки в нижней температурной области бейнитного превращения феррит стали $38 \mathrm{XC}$ имеет типичное реечное строение, а остаточный аустенит располагается в виде тонких прослоек между кристаллами бейнитного феррита. При боле высоких температурах образуется структура верхнего бейнита, в котором преобладают глобулярные, более крупные, чем при закалке в нижнем интервале превращения, кристаллы бейнитного феррита в сочетании с достаточно крупными участками остаточного аустенита.

Сталь 38XС широко используется в машиностроении для изготовления ответственных метизов, подвергаемых изотермической закалке, и выбор ее для исследования диктовался еще и тем обстоятельством, что в практике встречаются случаи, когда после термообработки вследствие нарушения технологических условий происходит образование верхнего бейнита, в результате чего не удается обеспечить требуемый уровень ударной вязкости. 
Данные о влиянии низкого отпуска на температуру $300{ }^{\circ} \mathrm{C}$ на ударную вязкость, твердость, количество остаточного аустенита и содержание в нем углерода в стали $38 \mathrm{XC}$ после изотермической закалки при температурах $360^{\circ} \mathrm{C}$ и $410^{\circ} \mathrm{C}$ с выдержками, обеспечивающими различную степень превращения, приведены в табл. 2.

Таблица 2 - Влияние термической обработки на механические свойства стали $38 \mathrm{XC}$, количество остаточного аустенита (О.А.) и содержание в нем углерода

\begin{tabular}{|c|c|c|c|c|c|c|}
\hline $\begin{array}{c}\text { Режим } \\
\text { изотермической } \\
\text { закалки } \\
\end{array}$ & $\begin{array}{c}\text { Режим } \\
\text { отпуска }\end{array}$ & 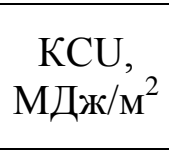 & $\begin{array}{c}\text { Твер- } \\
\text { дость, } \\
\text { НВ }\end{array}$ & $\begin{array}{l}\text { Кол-во } \\
\text { О.А., \% }\end{array}$ & $\begin{array}{c}\text { Параметр } \\
\text { решетки } \\
\text { O.А., нм } \\
\end{array}$ & $\begin{array}{c}\text { Содержание } \\
\text { углерода } \\
\text { в O.А. } \\
\end{array}$ \\
\hline $360^{\circ} \mathrm{C}, 3$ мин & Без отпуска & 0,6 & 401 & 16 & 0,3613 & 1,36 \\
\hline $360^{\circ} \mathrm{C}, 3$ мин & $300^{\circ} \mathrm{C}, 1$ ч & 1,1 & 388 & 13 & 0,3618 & 1,50 \\
\hline $360{ }^{\circ} \mathrm{C}, 10$ мин & Без отпуска & 0,9 & 388 & 18 & 0,3613 & 1,36 \\
\hline $360{ }^{\circ} \mathrm{C}, 10$ мин & $300^{\circ} \mathrm{C}, 1$ ч & 1,1 & 375 & 17 & 0,3616 & 1,45 \\
\hline $360^{\circ} \mathrm{C}, 25$ мин & Без отпуска & 1,0 & 388 & 16 & 0,3615 & 1,42 \\
\hline $360^{\circ} \mathrm{C}, 25$ мин & $300^{\circ} \mathrm{C}, 1$ ч & 1,2 & 375 & 15 & 0,3617 & 1,47 \\
\hline $410^{\circ} \mathrm{C}, 5$ мин & Без отпуска & 0,7 & 341 & 26 & 0,3606 & 1,18 \\
\hline $410^{\circ} \mathrm{C}, 5$ мин & $300^{\circ} \mathrm{C}, 1$ ч & 1,2 & 321 & 17 & 0,3616 & 1,45 \\
\hline $410^{\circ} \mathrm{C}, 10$ мин & Без отпуска & 1,0 & 321 & 31 & 0,3608 & 1,23 \\
\hline $410^{\circ} \mathrm{C}, 10$ мин & $300^{\circ} \mathrm{C}, 1$ ч & 1,2 & 311 & 21 & 0,3614 & 1,39 \\
\hline
\end{tabular}

Видно, что отпуск повышает значения ударной вязкости изотермически закаленной стали, имеющей в структуре различное соотношение бейнитного феррита, мартенсита и остаточного аустенита. Это справедливо как по отношению к реечному - нижнему бейниту, так и к глобулярному - верхнему бейниту. Такой отпуск после изотермической закалки при температуре $360{ }^{\circ} \mathrm{C}$ с выдержкой 3 мин и при температуре $410{ }^{\circ} \mathrm{C}$ с выдержками $5 \ldots 10$ мин

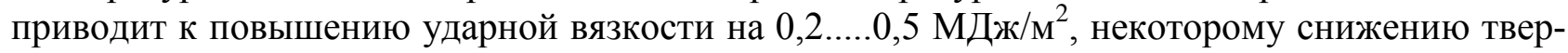
дости, существенному уменьшению количества остаточного аустенита и обогащению его углеродом в среднем на 0,2 \%. При увеличении времени изотермической выдержки, т. е. при дальнейшем развитии бейнитного превращения, которое сопровождается увеличением содержания углерода в остаточном аустените, а значит и возрастанием его стабильности, значения ударной вязкости после отпуска повышаются в среднем на 0,2 МДж/ ${ }^{2}$, а количество остаточного аустенита уменьшается незначительно.

При всех режимах изотермической закалки после низкотемпературного отпуска наблюдается повышение содержания углерода в остаточном аустените. Вероятно, это связано с тем, что при отпуске при температуре $300{ }^{\circ} \mathrm{C}$ бейнитное превращение продолжается, и некоторая часть остаточного аустенита превращается в бейнитный феррит без выделения карбидов. При этом количество остаточного аустенита уменьшается, а содержание углерода в нераспавшейся части остаточного аустенита увеличивается (табл. 2).

Таким образом, при сохранении бескарбидного бейнита в процессе нагрева и выдержки при температуре $300{ }^{\circ} \mathrm{C}$ изотермически закаленной стали $38 \mathrm{XC}$ не только происходит отпуск присутствующего в стали мартенсита, образовавшегося во время охлаждения от температуры изотермической закалки при непродолжительных выдержках, но и стабилизируется

Kaletin A.Yu. / Mechanical properties of the $38 \mathrm{KhS}$ steel after isothermal quenching in the bainitic 
присутствующий остаточный аустенит, и это обусловливает повышение вязкости стали с бейнитной структурой.

Приведенные результаты открывают новый аспект в назначении низкотемпературного отпуска, заключающийся не только в достижении снятия напряжений для изотермически заклеенных деталей из бейнитной стали, но и в дополнительном обогащении остаточного аустенита углеродом, его стабилизации , обеспечивающей повышение ударной вязкости стали в высокопрочном состоянии.

\section{4. Заключение}

Показано, что остаточный аустенит в бескарбидном бейните кремнистой стали после непрерывного охлаждения существенно обогащен по углероду и содержит значительную часть от общего содержания углерода в стали. Установлено, что отпуск при температуре $300{ }^{\circ} \mathrm{C}$ в течение $1 . . .2$ ч повышает значения ударной вязкости стали $38 \mathrm{XC}$ после изотермической закалки в бейнитном интервале температур, имеющей в структуре различное соотношение как реечного - нижнего, так и глобулярного - верхнего бейнита, и остаточного аустенита. Установлено, что при таком отпуске происходит стабилизация остаточного аустенита за счет заметного повышения в нем содержания углерода.

\section{Благодарность}

Работа выполнена в рамках государственного задания ФАНО России (тема «Кристалл», № 01201463333) при частичной поддержке проекта УрО РАН № 15-17-2-11. Электронно-микроскопическое исследование выполнено в ЦКП «Испытательный центр нанотехнологий и перспективных материалов» ИФМ УрО РАН.

\section{Список литературы}

1. Bhadeshia H. K. D. H. Bainite in Steels. - 3d ed. - London : The Institute of Materials. 2016. - 616 p. - ISBN-13: 978-1909662742.

2. Bojarski Z., Bold T. Structure and properties of carbide-free-bainite // Acta Metallurgica. 1974. - Vol. 22, iss. 10. - P. 1223-1234.

3. Caballero V. F. G., Bhadeshia H. K. D. H. Very strong bainite // Current Opinion in Solid State and Materials Science. - 2004. - Vol. 8, iss. 3. - P. 251-257.

4. Caballero F. G., Santofimia M. J., Garcia-Mateo C., Chao J., Garcia de Andres C. Theoretical design and advanced microstructure in super high strength steels // Materials and Design. 2009. - Vol. 30, iss. 6. - P. 2077-2083.

5. Caballero F. G., Roelofs H., Hasler St., Capdevila C., Chao J., Cornide J., Garcia-Mateo C. Influence of bainite morphology on impact toughness of continuously cooled cementite free bainitic steels // Materials Science and Technology. - 2012. - Vol. 28, iss. 1. - P. 95-102.

6. Low temperature bainite in steel with 0, $26 \mathrm{wt} \%$ C / M. Soliman, H. Mostafa, A. S. ElSabbah, H. Palkovski // Materials Science and Engineering A. - 2010. - Vol. 527, iss. 29-30. P. 7706-7713.

7. Счастливцев В. М., Калетина Ю. В., Фокина Е. А. Остаточный аустенит в легированных сталях. - Екатеринбург : РИО УрО РАН, 2014. - 236 с. - ISBN 978-5-7691-2384-9.

8. Carbide-free bainite in medium carbon steel / X. Y. Long, J. Kang, B. Lv, F. C. Zhang // Materials and Design. - 2014. - Vol. 64. - P. 237-245.

9. Carbide-free bainitic weld metal: a new concept in welding of armor steels / M. N. Krishna, R. G. D. Janaki, B. S. Murty, G. M. Reddy, T. G. P. Rao // Metallurgical and Materials Transactions B. $-2014 .-$ Vol. 45 , iss. 6. - P. 2327-2337.

10. Kaletin A. Yu., Ryzhkov A. G., Kaletina Yu. V. Enhancement of impact toughness of structural steels upon formation of carbide-free bainite // Physics of Metals and Metallography. 2015. - Vol. 116, no. 1. - P. 109-114. - DOI: 10.1134/S0031918X15010068 


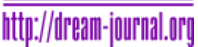

11. Kaletin A. Yu., Kaletina Yu. V. Evolution of Structure and Properties of Silicon Steels in the Austenite-Bainite Phase Transition // Physics of the Solid State. - 2015. - Vol. 57, iss. 1. P. 56-61. - DOI: 10.1134/S106378341501014X

12. Kaletin A. Yu., Kaletina Yu. V. Effect of low-temperature tempering on the properties of structural carbide-free bainitic steels // Diagnostics, Resource and Mechanics of Materials and Structures. - 2016. - Iss. 6. - P. 63-68. - URL: http://dream-journal.org/ /DREAM_Issue_6_2016_Kaletin_A.Yu._et_al._063_068.pdf 